Corresponding author: sbpierce@uw.edu

(C) 2016 Pierce et al. This article is distributed under the terms of the Creative Commons Attribution-NonCommercial License, which permits reuse and redistribution, except for commercial purposes, provided that the original author and source are credited.

Ontology terms: bilateral sensorineural hearing impairment; decreased distal sensory nerve action potential; gait ataxia; hypergonadotropic hypogonadism; impaired distal proprioception; impaired vibration sensation at ankles; infantile spasms; progressive external ophthalmoplegia; sensorimotor neuropathy

Published by Cold Spring Harbor Laboratory Press

doi: 10.1101/mcs.a001107

\section{Infantile onset spinocerebellar ataxia caused by compound heterozygosity for Twinkle mutations and modeling of Twinkle mutations causing recessive disease}

\author{
Sarah B. Pierce, ${ }^{1}$ Suleyman Gulsuner, ${ }^{1}$ Gail A. Stapleton, ${ }^{2}$ Tom Walsh, ${ }^{1}$ \\ Ming K. Lee, ${ }^{1}$ Jessica B. Mandell, ${ }^{1}$ Augusto Morales, ${ }^{3}$ Rachel E. Klevit, ${ }^{4}$ \\ Mary-Claire King, ${ }^{1,5}$ and R. Curtis Rogers ${ }^{2}$ \\ ${ }^{1}$ Department of Medicine (Medical Genetics), University of Washington, Seattle, Washington 98195, USA; \\ ${ }^{2}$ Greenwood Genetic Center, Greenville, South Carolina 29605, USA; ${ }^{3}$ Pediatric Neurology, Greenville Health \\ System, Greenville, South Carolina 29615, USA; ${ }^{4}$ Department of Biochemistry, University of Washington, \\ Seattle, Washington 98195, USA; ${ }^{5}$ Department of Genome Sciences, University of Washington, Seattle, \\ Washington 98195, USA
}

\begin{abstract}
Mutations in nuclear genes required for the replication and maintenance of mitochondrial DNA cause progressive multisystemic neuromuscular disorders with overlapping phenotypes. Biallelic mutations in C10orf2, encoding the Twinkle mitochondrial DNA helicase, lead to infantile-onset cerebellar ataxia (IOSCA), as well as milder and more severe phenotypes. We present a 13-year-old girl with ataxia, severe hearing loss, optic atrophy, peripheral neuropathy, and hypergonadotropic hypogonadism. Whole-exome sequencing revealed that the patient is compound heterozygous for previously unreported variants in the C10orf2 gene: a paternally inherited frameshift variant (c.333delT; p.L112Sfs*3) and a maternally inherited missense variant (c.904C>T; p.R302W). The identification of novel C10orf2 mutations extends the spectrum of mutations in the Twinkle helicase causing recessive disease, in particular the intermediate IOSCA phenotype. Structural modeling suggests that the p.R302W mutation and many other recessively inherited Twinkle mutations impact the position or interactions of the linker region, which is critical for the oligomeric ring structure and activity of the helicase. This study emphasizes the utility of whole-exome sequencing for the genetic diagnosis of a complex multisystemic disorder.
\end{abstract}

\section{INTRODUCTION}

The mitochondrial genome encodes 13 protein subunits of the respiratory chain complexes, as well as ribosomal and transfer RNAs required for their translation. The remaining proteins required for mitochondrial structure and function are encoded by the nuclear genome. Mutations in nuclear genes involved in the maintenance of the mitochondrial genome lead to deletions or depletion of mitochondrial DNA (mtDNA). The loss of mtDNA leads to respiratory chain dysfunction causing a number of progressive multisystemic neuromuscular disorders (for review, see Copeland 2014). Genetic heterogeneity and the overlapping 
COLD SPRING HARBOR Molecular Case Studies
Modeling Twinkle mutations causing recessive disease and complex nature of the phenotypes make it difficult to predict which gene will be mutated in an affected individual.

Mitochondrial DNA depletion syndrome 7 (MTDPS7; OMIM 271245) is associated with a variable phenotype that may include infantile or adult-onset spinocerebellar ataxia, ophthalmoplegia, encephalopathy, seizures, and hepatic failure. Infantile onset spinocerebellar ataxia (IOSCA) is one of the phenotypes seen in MTDPS7. It is characterized by normal development for approximately the first year of life followed by the development of muscle hypotonia, ataxia, ophthalmoplegia, optic atrophy, hearing loss, sensory axonal neuropathy, epilepsy, and female hypogonadism (Koskinen et al. 1994). First described in Finland, IOSCA was shown to be caused by homozygosity for a founder mutation in the C10orf2 gene (c.1708A>G, p.Y508C) (Nikali et al. 2005). C10orf2 encodes the mitochondrial DNA helicase Twinkle, which is essential for mtDNA replication (McKinney and Oliveira 2013). A limited number of additional C10orf2 mutations have since been reported as causing IOSCA, as well as milder and more severe recessive phenotypes (Hakonen et al. 2007; Sarzi et al. 2007; Dündar et al. 2012; Goh et al. 2012; Hartley et al. 2012; Faruq et al. 2013; Prasad et al. 2013; Morino et al. 2014; Park et al. 2014). The identification of new cases will help to define the spectrum of C10orf2 mutations that result in recessive disease and provide a more complete understanding of the range of phenotypes caused by these mutations. We describe a 13-yr-old girl with clinical features of IOSCA and compound heterozygosity for novel variants in C10orf2.

\section{RESULTS}

\section{Clinical Presentation}

A 13-year-old female was evaluated for her history of ataxia, severe hearing loss, optic atrophy, and peripheral neuropathy (Fig. 1A). She was the first child of unrelated American parents of European descent, born healthy after a normal pregnancy and delivery; birth weight was $3.997 \mathrm{~kg}$ and length was $57 \mathrm{~cm}$. She developed normally for the first 8-9 mo, sitting and crawling by 6 mo of age and pulling up at 7.5 mo. Hypotonia was noted by 10 mo of age. Infantile spasms occurred at 12 mo of age, with electroencephalography (EEG) indicating modified hypsarrhythmia. Seizures resolved 6-8 wk after treatment with topiramate and pyridoxine, which was added empirically, and have not recurred. EEG results were normal at 5 and $13 \mathrm{yr}$ of age. At the time of the seizures, levels of urine organic acids, ammonia, plasma amino acids, and serum lactate and pyruvate were normal. Development slowed after the onset of seizures. Walking was achieved at age $3 \mathrm{yr}$, but balance was poor. Hearing impairment became evident at 3 yr of age and auditory neuropathy was diagnosed. Optic neuropathy was diagnosed at 5 yr of age. Electroretinography was normal. Evaluation for additional neuropathy identified peripheral neuropathy in the lower legs and feet. Nerve conduction velocities performed at $10 \mathrm{yr}$ of age indicated mild axonopathy with decreased velocity and reduced amplitude. Brain imaging studies were normal as determined by magnetic resonance imaging at $12 \mathrm{mo}, 3 \mathrm{yr}$, and $4.5 \mathrm{yr}$ of age, and computed tomography (CT) scan at $10 \mathrm{yr}$ of age. Additional laboratory testing included normal blood urea nitrogen, creatinine, total serum protein, bilirubin, albumin, liver transaminases, long chain fatty acids, plasma acylcarnitine profile, serum a-fetoprotein, metabolic screen, and spinal fluid lactate $(1.6 \mathrm{mmol} / \mathrm{L}$; normal range $0.8-2.4)$. Initial genetic analysis revealed a normal $46, X X$ karyotype and normal results from microarray analysis using the Human SNP 6.0 array (Affymetrix), sequencing of GJB2 (encoding connexin 26) and POLG, and sequencing of the mitochondrial genome. Results of a 103-gene epilepsy panel test revealed maternally inherited variants of unknown significance (VUSs) in TSEN54 and CNTNAP2 and a paternally inherited VUS in MAGI2 (http://www.ggc. org/diagnostic/tests-costs/test-finder/ngs-epilepsy-seizure-panel.html). 
COLD SPRING HARBOR Molecular Case Studies
Modeling Twinkle mutations causing recessive disease
A

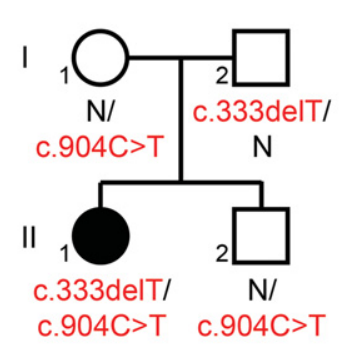

C
B

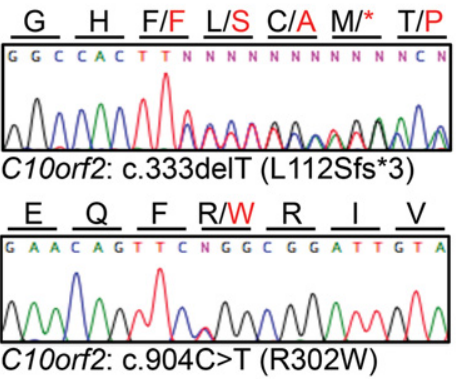

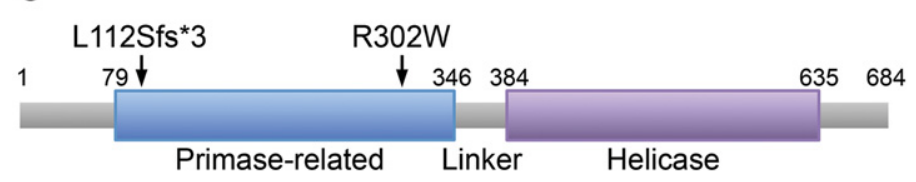

D

H. sapiens 295 LPYLEQFRRIVFWLG

M. musculus 296 LPYLEQFRRIVFWLG

G. galus 301 LPYLEQFRRVTLWLG

D. rerio 336 LPYLEQFKKVTLWLG

D. melanogaster 261 LPALERFKELIFWLH

C. elegans 209 LPYLEEFDKIYLWFP

Bacteriophage T7 193 YEYFDQFEQIILMFD

Figure 1. Compound heterozygosity for C10orf2 mutations. (A) Pedigree of family of affected patient II-1; C10orf2 genotypes are indicated. (B) Validation by Sanger sequencing of C10orf2 mutations identified by exome sequencing. Codon changes are indicated in red. $(C)$ Domain architecture of the Twinkle protein. (D) Protein sequence alignment of orthologs of the Twinkle protein, encoded by C10orf2, showing the region surrounding the mutated arginine residue, R302 (indicated in red).

Examination of the patient at age 13 revealed ataxia, pes cavus, decreased vibratory sensation and proprioception, hyporeflexia, ophthalmoplegia without ptosis, and bilateral optic atrophy. No abnormal pigment was present in the retina. She walks on the outside of the foot, with gait studies showing a mild increased femoral anteversion, and suffers frequent falls as a result of ataxia; she uses a wheelchair for long distances. She has mild intellectual disability, requiring special education services in a self-contained classroom for students with orthopedic impairment. Primary amenorrhea and lack of breast development prompted an endocrine evaluation, which revealed elevated follicle-stimulating hormone (FSH; >86 mIU/ $\mathrm{mL}$; normal range 0.7-11.0) and luteinizing hormone $(\mathrm{LH} ; 18.76 \mathrm{mlU} / \mathrm{mL}$; normal range 0.04-10.80). A uterus and ovaries were undetected by ultrasound, consistent with hypergonadotropic hypogonadism. Recently, the patient has experienced two viral illnesses that have been associated with episodes of worsening ocular paralysis. The two parents and a younger brother have none of the above signs.

\section{Whole-Exome Sequencing}

Genomic DNA samples from all family members were evaluated by whole-exome sequencing. The presence of a single affected female individual in this family is consistent with autosomal recessive inheritance or with a dominant de novo mutation. We filtered variants of the proband to identify potentially damaging homozygous, compound heterozygous, and de novo variants. Only one result matched any of these criteria: the proband was compound heterozygous for C10orf2 c.333delT (p.L112Sfs*3) at Chr 10:102,748,300, inherited from her father, and C10orf2 c.904C>T (p.R302W) at Chr 10:102,748,871, inherited from her 


\begin{tabular}{|c|c|c|c|c|c|c|}
\hline $\begin{array}{l}\text { Chr:position } \\
\text { GRCh37(hg19) }\end{array}$ & $\begin{array}{l}\text { HGVS } \\
\text { cDNA }\end{array}$ & $\begin{array}{l}\text { HGVS } \\
\text { protein }\end{array}$ & $\begin{array}{l}\text { Type of } \\
\text { variant }\end{array}$ & $\begin{array}{l}\text { Predicted } \\
\text { effect }\end{array}$ & Genotype & $\begin{array}{c}\text { Parent of } \\
\text { origin }\end{array}$ \\
\hline $10: 102,748,300$ & c.333delT & p.(L112Sfs*3) & Deletion & $\begin{array}{l}\text { Frame shift and } \\
\text { truncation }\end{array}$ & Heterozygous & Father \\
\hline $10: 102,748,871$ & c. $904 \mathrm{C}>\mathrm{T}$ & p.(R302W) & Substitution & Missense & Heterozygous & Mother \\
\hline
\end{tabular}

HGVS, Human Genome Variation Society; cDNA, complementary DNA.

mother (Tables 1 and 2; Fig. 1A,B). The unaffected brother is heterozygous for C10orf2 c.904C>T. Among 60,628 individuals with whole-exome data in the Exome Aggregation Consortium (ExAC) database, one individual carried C10orf2 c.904C $>\mathrm{T}$ and none carried C10orf2 c.333delT.

C10orf2 encodes the Twinkle DNA helicase, which unwinds double-stranded DNA and functions with polymerase $\gamma$ (POLG) during mtDNA replication (McKinney and Oliveira 2013). As the only replicative helicase in mammalian mitochondria, Twinkle is essential for mtDNA replication (Milenkovic et al. 2013). Twinkle contains three functional domains: an amino-terminal primase, a linker region, and a carboxy-terminal helicase (Fig. 1C; Shutt and Gray 2006). The Twinkle p.L112Sfs*3 variant is predicted to yield a truncated protein that would lack most of the primase domain and all of the linker and helicase domains and is unlikely to be functional. The missense variant p.R302W is predicted to be damaging by PolyPhen-2 (score 1.00) and SIFT Blink $(P=0.00)$. Arginine at residue 302 is conserved in virtually all mammals and arginine or similarly charged lysine is conserved in virtually all vertebrates (Fig. 1D). Bulky hydrophobic residues such as tryptophan are never present at this position.

\section{Structural Modeling of Twinkle p.R302W}

We investigated the possible consequences of the Twinkle p.R302W missense substitution by examining the three-dimensional structure of bacteriophage T7 primase-helicase gp4, a Twinkle ortholog. Studies of prokaryotic primase-helicase enzymes suggest that Twinkle

\begin{tabular}{lcccc}
\hline \multicolumn{4}{l}{ Table 2. Exome sequencing results and variant filtering } \\
\hline & II-1 & II-2 & I-1 & I-2 \\
\hline Total number of reads & $79,999,788$ & $72,975,641$ & $85,959,236$ & $78,811,279$ \\
\% of mapped reads & 98.25 & 97.97 & 98.66 & 98.66 \\
\% of targeted bases covered at $\geq 8 \times$ & 96.73 & 96.67 & 97.13 & 97.23 \\
\% of targeted bases covered at $\geq 20 \times$ & 92.42 & 91.59 & 94.14 & 93.93 \\
Average coverage, $\times$ & 79.02 & 71.07 & 99.65 & 89.97 \\
All coding and splice variants & 22,908 & 22,671 & 23,073 & 22,257 \\
Rare variants ${ }^{a}$ & 264 & 232 & 267 & 246 \\
Predicted damaging to protein function ${ }^{b}$ & 83 & 71 & 76 & 70 \\
De novo damaging variants & 0 & 1 & - & - \\
Damaging variants fitting recessive model & 2 & - & - & - \\
\hline
\end{tabular}

a Variants were excluded if minor allele frequency was $\geq 0.001$ in the 1000 Genomes Project or the National Heart, Lung, and Blood Institute (NHLBI) Exome Sequencing Project or if there were more than 60 carriers on the Exome Aggregation Consortium (ExAC) database.

b Variants predicted damaging to protein function were truncating mutations, splice site mutations predicted to alter transcripts, and missense variants with PolyPhen-2 score of $\geq 0.8$ and SIFT score of $\leq 0.05$. 
C OLD SPR ING HARBOR Molecular Case Studies
Modeling Twinkle mutations causing recessive disease

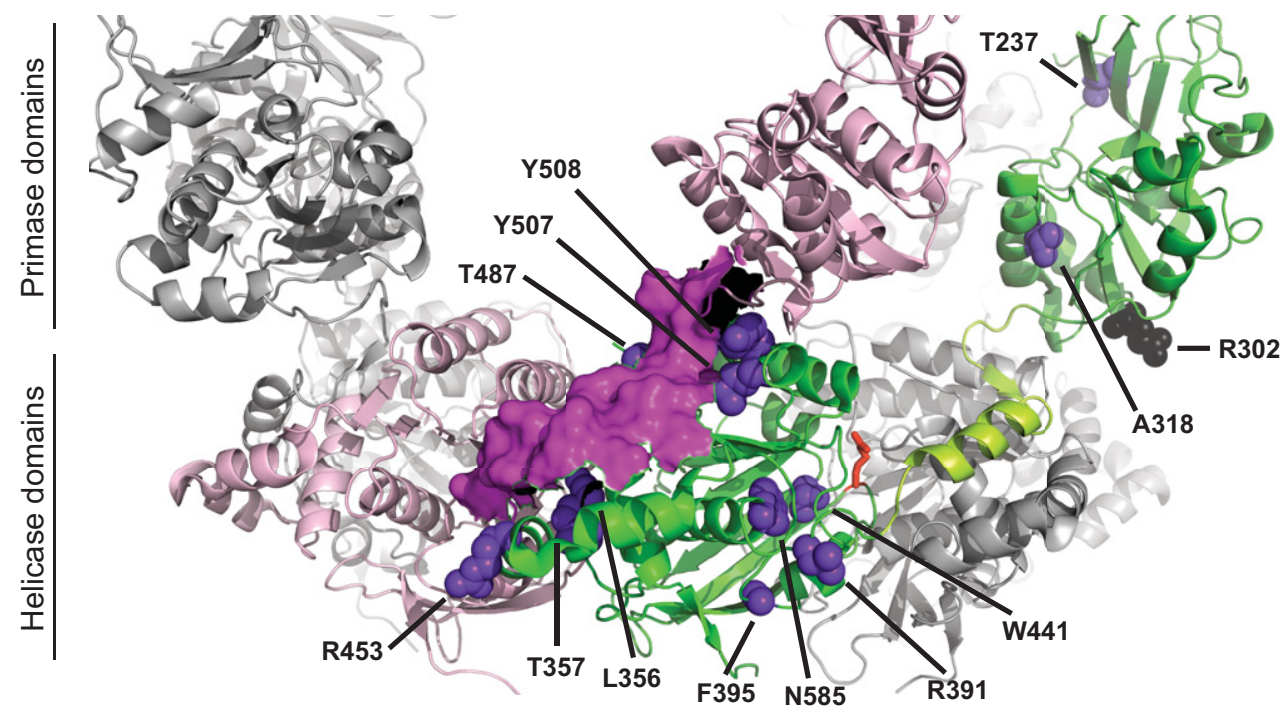

Figure 2. Crystal structure of the Twinkle ortholog gp4 from T7 bacteriophage: Two subunits of the heptameric primase-helicase gp4 (PDB ID 1057) are shown in pink and green; remaining subunits are shown in gray. Helicase domains compose the bottom ring, and primase domains of three subunits (green, pink, and one gray) appear to hover on top. The linker region of the pink subunit is shown in dark pink surface representation; its interior surface appears black where visible; the linker region of the green subunit is light green. All other domains and subunits are shown as cartoons. The residue corresponding to the p.R302W mutation in this report is shown in black spheres and residues corresponding to other Twinkle mutations causing recessive disease are shown as purple spheres; residues are indicated with the Twinkle residue numbers. The catalytic residue p.R609 is shown in red sticks. The residue corresponding to p.P83 was not included in the crystallized protein.

proteins likely form hexameric or heptameric ring structures, in which the tightly packed ring of helicase domains is topped with a more loosely arranged crown of primase domains (Fig. 2; Toth et al. 2013). The Twinkle residue p.R302 is near the carboxy-terminal end of the primase domain. The gp4 residue p.E200, orthologous to Twinkle p.R302, is on the outer surface of the primase ring, facing down toward the helicase ring. The p.R302W substitution would place a bulky hydrophobic residue, which is most often found buried in the hydrophobic protein core, on the protein surface, possibly affecting the protein's stability or solubility. Interestingly, the mutation p.R303W, which replaces the adjacent arginine residue with a tryptophan and is also found in human patients, results in reduced thermostability of the mutant protein (Longley et al. 2010).

\section{Structural Modeling of Twinkle Mutations Causing Recessive Disease}

Thirteen additional Twinkle missense mutations have been previously identified as causing recessive disease. For comparison, we also mapped the sites of these mutations onto the structure of gp4 (Fig. 2). Strikingly, six of the affected residues flank the linker region of the adjacent subunit. The linker is involved in oligomerization and required for helicase activity (Milenkovic et al. 2013). In particular, the residues orthologous to p.L456, p.T457, and p.R463 are in helices that appear to support the path of the linker. Consistent with this, structural modeling previously suggested that p.T457 plays a role in subunit interactions (Sarzi et al. 2007). As we previously reported, the residue orthologous to p.Y507 is predicted to interact directly with the linker of the neighboring subunit (Morino et al. 2014), as does the adjacent residue orthologous to P.Y508. In addition, as we previously noted, the residues 
orthologous to p.R391 and p.Y441 interact with each other and are proximal to the linker domain of their own subunit. Thus, eight of the mutations may disrupt the position or interactions of the linker region, which is critical for flexibility and closure of the oligomeric ring structure (Toth et al. 2013). One of the remaining mutations, p.N585S, is likely to impact the position of a critical catalytic residue and thus affect enzyme activity (Morino et al. 2014). Possible effects of the other mutations, including p.R302W and three others in the primase domain, include impacts on subunit stability or on single-stranded DNA binding, which is necessary for optimal helicase activity and for which the primase domain is required (Holmlund et al. 2009).

\section{DISCUSSION}

Recessive conditions caused by mutations in Twinkle have been grouped together as MTDPS7. The variable phenotypes of MTDPS7 include IOSCA (Nikali et al. 2005; Dündar et al. 2012; Hartley et al. 2012; Faruq et al. 2013; Park et al. 2014), the more severe hepatocerebral syndrome (Hakonen et al. 2007; Sarzi et al. 2007; Goh et al. 2012; Prasad et al. 2013), involving early liver damage, and the less severe Perrault syndrome (OMIM 233400), which is limited to hearing loss, female hypergonadotropic hypogonadism, and ataxia (Fig. 3; Morino et al. 2014). Mutations leading to any of these phenotypes can cause histological changes detectable by muscle biopsy. However, mtDNA depletion has only been detected in cases of IOSCA and hepatocerebral syndrome by examining mtDNA copy number in brain and liver; mtDNA depletion was not detectable in muscle (Hakonen et al. 2008). Muscle mitochondrial respiratory chain enzyme activities are normal in cases of IOSCA and Perrault syndrome. The phenotype and clinical course of the patient described here are most similar to IOSCA, as described in patients who are homozygous for the Finnish founder allele. The follow-up of a cohort of Finnish IOSCA patients into adulthood indicates that the majority of patients develop severe epilepsy and many develop psychiatric symptoms (Lönnqvist et al. 2009). The use of certain antiseizure medications, such as valproate, can lead to dangerous liver toxicity in IOSCA patients (Lönnqvist et al. 2009), as seen in other mtDNA depletion syndromes, such as POLG disorders (Isohanni et al. 2011).

Including the case reported here, 12 C10orf2 genotypes have been reported as causing recessive disease (Fig. 3), with half of these genotypes causing the moderate IOSCA phenotype. With the exception of the Finnish founder allele, p.Y508C, homozygous or compound heterozygous C10orf2 mutations have been identified in single cases or small families of many different ancestries. Dominant progressive external ophthalmoplegia type 3 (PEOA3, OMIM 609286) is also caused by mutations in C10orf2 and at least 40 causative mutations have been identified (Morino et al. 2014). There is no overlap between the mutations causing dominant and recessive phenotypes.

Understanding and predicting the functional impact of individual Twinkle variants is particularly challenging. Although many of the mutations causing recessive phenotypes are likely to impact the position of the linker region, many of the mutations causing dominant PEOA3 are also clustered within or near the linker region. In several cases mutation of adjacent amino acids causes distinct recessive and dominant phenotypes (Morino et al. 2014). Recent structural modeling and biochemical analysis of the Finnish founder allele p.Y508C suggests that the substitution disrupts the coupling between NTP hydrolysis and singlestranded DNA binding and translocation (Nikkanen et al. 2016), which is important for the sequential and cooperative catalytic activity of the different subunits within the ring structure (Singleton et al. 2000). However, a thorough evaluation of 20 mutations of Twinkle, causing both dominant and recessive disease, found no simple relationship between perturbations of the biochemical properties of Twinkle and the severity of clinical phenotypes caused by 


\begin{tabular}{|c|c|c|c|c|c|c|c|c|c|c|c|c|}
\hline \multirow{2}{*}{ Mutations } & \multicolumn{6}{|c|}{ IOSCA } & \multicolumn{4}{|c|}{$\begin{array}{c}\text { Hepatocerebral } \\
\text { syndrome }\end{array}$} & \multicolumn{2}{|c|}{$\begin{array}{c}\text { Perrault } \\
\text { syndrome }\end{array}$} \\
\hline & 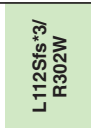 & 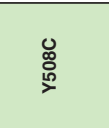 & 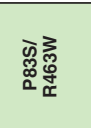 & 衣 & 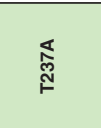 & 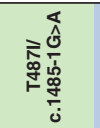 & $\begin{array}{l}\text { Fo } \\
\text { कo } \\
\text { 产桌 }\end{array}$ & 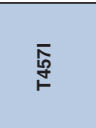 & 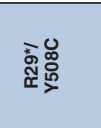 & 뱅 & 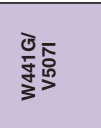 & 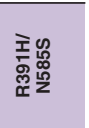 \\
\hline Ethnicity & Eur & Fin & Eng & Trk & Ind & Kor & Fin & Alg & NA & Pak & Gre/Eur & Jpn \\
\hline Age of onset & $<1 \mathrm{yr}$ & $<1.5 \mathrm{yr}$ & $<1 \mathrm{yr}$ & $>1 \mathrm{yr}$ & $<1 \mathrm{yr}$ & $>1 \mathrm{yr}$ & $6 \mathrm{mo}$ & newborn & newborn & newborn & $>6 \mathrm{yr}$ & $>7 \mathrm{yr}$ \\
\hline Life span & $>13 \mathrm{yr}$ & $>48 \mathrm{yr}$ & $5 \mathrm{yr}$ & $>7 \mathrm{yr}$ & $>21 \mathrm{yr}$ & $>23 \mathrm{yr}$ & $4-5 \mathrm{yr}$ & $2-3 \mathrm{yr}$ & $6 \mathrm{mo}$ & 4-6 mo & $>36 \mathrm{yr}$ & $>40 \mathrm{yr}$ \\
\hline Citations & This study & $\begin{array}{l}\text { Koskinen } \\
\text { et al. 1994; } \\
\text { Nikali } \\
\text { et al. 2005; } \\
\text { Lönnqvist } \\
\text { et al. 2009; } \\
\text { Hakonen } \\
\text { et al. } 2008\end{array}$ & $\begin{array}{l}\text { Hartley } \\
\text { et al. } 2012\end{array}$ & $\begin{array}{l}\text { Dündar } \\
\text { et al. } 2012\end{array}$ & $\begin{array}{c}\text { Faruq } \\
\text { et al. } 2013\end{array}$ & $\begin{array}{c}\text { Park } \\
\text { et al. } 2014\end{array}$ & $\begin{array}{l}\text { Hakonen } \\
\text { et al. } 2007\end{array}$ & $\begin{array}{c}\text { Sarzi } \\
\text { et al. } 2007\end{array}$ & $\begin{array}{l}\text { Goh } \\
\text { et al. } 2012\end{array}$ & $\begin{array}{l}\text { Prasad } \\
\text { et al. } 2013\end{array}$ & $\begin{array}{l}\text { Morino } \\
\text { et al. } 2014\end{array}$ & $\begin{array}{l}\text { Morino } \\
\text { et al. } 2014\end{array}$ \\
\hline \multicolumn{13}{|l|}{ Clinical signs } \\
\hline Normal early milestones & $\diamond$ & 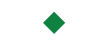 & 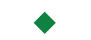 & $\bullet$ & 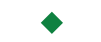 & $\bullet$ & $\bullet$ & & $\bullet$ & & $\bullet$ & $\bullet$ \\
\hline Psychomotor delay & $>$ & $\bullet$ & 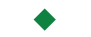 & 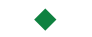 & $\diamond$ & 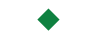 & 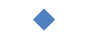 & $>$ & $>$ & $\bullet$ & & \\
\hline Ataxia & 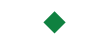 & 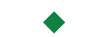 & n.a. & $>$ & 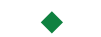 & $>$ & 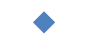 & n.a. & n.a. & n.a. & 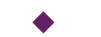 & 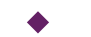 \\
\hline Athetosis & & $\bullet$ & 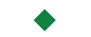 & $>$ & $\bullet$ & 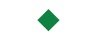 & $\nabla$ & n.a. & & n.a. & & \\
\hline Hyporeflexia & $\diamond$ & $\diamond$ & $\diamond$ & $\bullet$ & $\bullet$ & 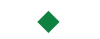 & $>$ & $\diamond$ & n.a. & n.a. & $\bullet$ & $\bullet$ \\
\hline Hypotonia & $\bullet$ & $\bullet$ & $>$ & $>$ & $\bullet$ & & 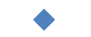 & 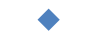 & $>$ & 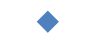 & & \\
\hline Peripheral neuropathy & 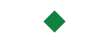 & $\bullet$ & $>$ & $>$ & $>$ & $>$ & 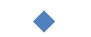 & 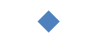 & n.a. & n.a. & $>$ & 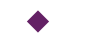 \\
\hline Hearing loss & $>$ & $\bullet$ & n.a. & $>$ & $>$ & 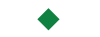 & $>$ & n.a. & $>$ & n.a. & $\bullet$ & $\diamond$ \\
\hline Ophthalmoplegia & 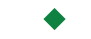 & $\bullet$ & $\diamond$ & $\diamond$ & & & $\diamond$ & n.a. ${ }^{a}$ & n.a. ${ }^{b}$ & n.a. ${ }^{a}$ & & $\diamond$ \\
\hline Nystagmus & & n.a. & 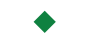 & & $>$ & & 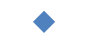 & n.a. ${ }^{a}$ & & n.a. ${ }^{a}$ & 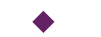 & 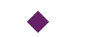 \\
\hline Scoliosis & & $\bullet$ & n.a. & n.a. & $\diamond$ & 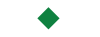 & n.a. & n.a. & n.a. & n.a. & & \\
\hline Liver involvement & & & & & & & 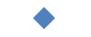 & $\nabla$ & $>$ & $\bullet$ & & \\
\hline Kidney involvement & & & & & & & & & & $\bullet$ & & \\
\hline \multicolumn{13}{|l|}{ Laboratory findings } \\
\hline Neuroimaging abnormal & & $\diamond$ & $>$ & $>$ & 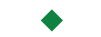 & 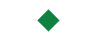 & 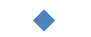 & $>$ & & & & $\diamond$ \\
\hline Nerve conduction studies abnormal & $\diamond$ & $\bullet$ & 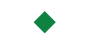 & 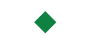 & $\bullet$ & 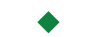 & n.a. & n.a. & n.a. & n.a. & n.a. & n.a. \\
\hline Electromyography abnormal & n.a. & $\diamond$ & n.a. & 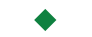 & & $>$ & $>$ & n.a. & n.a. & n.a. & $\bullet$ & $\diamond$ \\
\hline Electroencephalography abnormal & 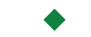 & $\bullet$ & $\diamond$ & & & & $\bullet$ & n.a. & & 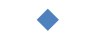 & n.a. & n.a. \\
\hline Lactate elevated & & & $>$ & & & $>$ & 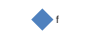 & $>$ & $>$ & $\diamond$ & 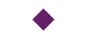 & 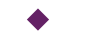 \\
\hline Pyruvate elevated & & & n.a. & & n.a. & & & n.a. & n.a. & 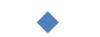 & n.a. & 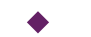 \\
\hline Lactate/pyruvate ratio elevated & & & n.a. & & n.a. & 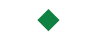 & n.a. & n.a. & n.a. & $\bullet$ & n.a. & $\bullet$ \\
\hline Liver enzymes elevated & & $>$ & $\diamond$ & & & & $\bullet$ & $\diamond$ & 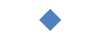 & $\bullet$ & n.a. & n.a. \\
\hline Creatine kinase elevated & n.a. & $\bullet$ & n.a. & n.a. & n.a. & & n.a. & $\diamond$ & n.a. & & n.a. & $\bullet$ \\
\hline$\alpha$-fetoprotein elevated & & & $\bullet$ & n.a. & & n.a. & $\diamond$ & n.a. & 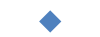 & n.a. & n.a. & n.a. \\
\hline Muscle biopsy abnormal $^{\mathrm{h}}$ & n.a. & 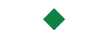 & $>$ & & n.a. & $>$ & $>$ & $\bullet$ & & & $\bullet$ & n.a. \\
\hline Nerve biopsy abnormal' & n.a. & 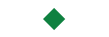 & $>$ & $\bullet$ & n.a. & $>$ & $>$ & n.a. & & n.a. & n.a. & n.a. \\
\hline Respiratory chain deficiency & n.a. & & & n.a. & n.a. & & 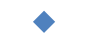 & 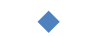 & n.a. & & & n.a. \\
\hline mtDNA depletion & n.a. & brain, liver & n.a. & n.a. & n.a. & n.a. & liver & liver & liver & n.a. & n.a. & n.a. \\
\hline mtDNA deletion & n.a. & & n.a. & n.a. & n.a. & $>$ & & & n.a. & n.a. & n.a. & n.a. \\
\hline
\end{tabular}

Figure 3. Phenotypic features of cases with recessive IOSCA, hepatocerebral syndrome, and Perrault syndrome caused by mutations in the $\mathrm{C} 10$ orf2 gene. Colored symbols indicate the presence of clinical signs and laboratory findings in patients with each genotype. Patients homozygous for p.T457I and p.F395L mutations had abnormal eye movements ( $\left.{ }^{(}\right)$. The p.R29*/p.Y508C compound heterozygous patient had a dysconjugate gaze $\left({ }^{b}\right)$. Ophthalmic signs included optic atrophy $\left({ }^{(}\right)$and delayed or absent visual-evoked potentials $\left({ }^{d}\right)$. Seizure activity was suspected in the p.R29*/p.Y508C compound heterozygous patient ( ${ }^{ }$). In some patients lactate was mildly or inconsistently elevated $\left({ }^{\circ}\right)$. Patients homozygous for the p.Y508C mutation had elevated liver enzymes only when treated with valproate $\left({ }^{(9}\right.$ ). Abnormal muscle biopsies showed fiber type grouping, atrophy of type II fibers, and/or COX-negative fibers $\left({ }^{h}\right)$. Abnormal nerve biopsies showed loss of myelinated nerve fibers ('). The p.T487//c.1485-1G >A compound heterozygous patients carried the heteroplasmic mtDNA deletion m.8470_13446del4977, which is commonly associated with progressive external ophthalmoplegia (j). Eur, European; Fin, Finnish; Eng, English; Trk, Turkish; Ind, Indian; Kor, Korean; Alg, Algerian; Pak, Pakistani; Gre, Greek; Jpn, Japanese; n.a., not available. 
COLD SPRING HARBOR Molecular Case Studies
Modeling Twinkle mutations causing recessive disease the mutations (Longley et al. 2010). Thus, subtle changes in enzyme activity, structure, or stability may be enough to cause disease, with the clinical outcome influenced by the specific combination of alleles.

The progressive multisystemic phenotype of our patient led to the suspicion of a mitochondrial disorder; however, biochemical indicators in blood, urine, and spinal fluid were lacking. The inability to detect mtDNA or respiratory chain defects in muscle biopsies of IOSCA patients and the inconsistent elevation of serum or spinal fluid lactate make it challenging to reach a definitive diagnosis of mitochondrial dysfunction in these cases. In addition, the features of IOSCA overlap considerably with those of other multisystemic disorders, making it difficult to predict a genetic cause. Our results emphasize the utility of wholeexome sequencing for the genetic diagnosis of a complex multisystemic disorder and identified novel Twinkle mutations as the cause of IOSCA. Because of the complex phenotypes of mitochondrial disorders, disease allele identification by massively parallel sequencing is now the gold standard for evaluation (Parikh et al. 2015).

\section{METHODS}

\section{Genomics}

Genomic DNA was isolated from blood and evaluated by whole-exome sequencing as previously described with some modifications (Walsh et al. 2010; Gulsuner et al. 2013). Genomic DNA libraries were captured with NimbleGen VCRome v2.1 (Yang et al. 2013), and then sequenced on an Illumina HiSeq 2500. Paired-end sequence reads (2 × $100 \mathrm{bp})$ were collected, filtered for quality, and aligned to exome targets using Burrows-Wheeler alignment (BWA), and then genotypes were called using the Genome Analysis Toolkit (GATK). At least $97.13 \%$ of targeted bases were covered at $\geq 8 \times$ in all family members (Table 2). Artifacts and common variants were excluded by comparison with $>1000$ exomes previously sequenced in our laboratory and with frequencies in the ExAC database (http ://exac.broadinstitute.org), the NHLBI Grand Opportunity (GO) Exome Sequencing Project (https://esp.gs.washington.edu), and the 1000 Genomes Project (http://www .1000 genomes.org). Variants were classified by predicted function as nonsense mutations, frameshift mutations, variants within 1 bp of a splice site, and missense variants. Missense mutations were evaluated for predicted effect on protein function based on conservation at the variant site and by using in silico tools PolyPhen-2 (http://genetics.bwh.harvard. edu/pph2/) and SIFT (Sorting Intolerant From Tolerant; http://sift.bii.a-star.edu.sg). All missense variants predicted to be damaging and all variants predicted to lead to protein truncation were retained as candidate alleles. Candidate variants were validated by Sanger sequencing, and then tested for cosegregation with the phenotype in all family members. Primers used for validation were $5^{\prime}$-ccagtgttgcctgtaactgc- $3^{\prime}$ and $5^{\prime}$-ccaagggaagacaagactgc -3' for C10orf2 c.333delT and 5'-agtcgtcgagatgctgaggt-3' and 5'-ggccaaccttcttttcaaca-3' for C10orf2 c.904C>T.

\section{Protein Structure Modeling}

Structural roles of Twinkle residues were predicted by comparison with the structure of bacteriophage T7 primase-helicase gp4 (PDB 1057). Orthologous residues were identified by amino acid sequence alignment with ClustalW2. Structures were visualized and cartoons rendered using the PyMOL Molecular Graphics System, version 1.5.0.4, Schrödinger, LLC. 


\section{ADDITIONAL INFORMATION}

\section{Data Deposition and Access}

Our patient consent does not permit us to make patient sequence data publicly available. The C10orf2 variants identified in this study have been deposited in ClinVar (http:// www.ncbi.nlm.nih.gov/clinvar/) under the accession numbers SCV000267647 and SCV000267648 and in the Leiden Open Variation Database (LOVD) (http://databases.lovd. $\mathrm{nl} /$ shared/genes/C10orf2) under variant IDs 0000091271 and 0000091272.

\section{Ethics Statement}

The study was approved by the human subjects committee of the University of Washington and the methods were carried out in accordance with the approved guidelines. All subjects provided written informed consent.

\section{Acknowledgments}

We thank the family for their willingness to participate in this study.

\section{Author Contributions}

S.B.P. and M.-C.K. were responsible for study concept and design and data analysis and interpretation. S.G. analyzed and interpreted exome data. G.A.S. and J.B.M. were responsible for patient counseling and communication. T.W. performed exome sequencing. M.K.L. analyzed exome data. A.M. and R.C.R. performed diagnostic assessments and obtained clinical data. S.B.P. designed and performed validation analysis. R.E.K. performed protein structure analysis. S.B.P. wrote the manuscript and prepared figures. T.W., R.E.K., M.-C.K., and R.C.R. contributed to manuscript revisions.

\section{Funding}

This work was supported by unrestricted gifts to the King lab. M.-C.K. is an American Cancer Society Professor.

\section{REFERENCES}

Copeland WC. 2014. Defects of mitochondrial DNA replication. J Child Neurol 29: 1216-1224.

Dündar H, Ozgül RK, Yalnızoğlu D, Erdem S, Oğuz KK, Tuncel D, Temuçin CM, Dursun A. 2012. Identification of a novel Twinkle mutation in a family with infantile onset spinocerebellar ataxia by whole exome sequencing. Pediatr Neurol 46: 172-177.

Faruq M, Narang A, Kumari R, Pandey R, Garg A, Behari M, Dash D, Srivastava A, Mukerji M. 2013. Novel mutations in typical and atypical genetic loci through exome sequencing in autosomal recessive cerebellar ataxia families. Clin Genet 86: 335-341.

Goh V, Helbling D, Biank V, Jarzembowski J, Dimmock D. 2012. Next-generation sequencing facilitates the diagnosis in a child with twinkle mutations causing cholestatic liver failure. J Pediatr Gastroenterol Nutr 54: 291-294.

Gulsuner S, Walsh T, Watts AC, Lee MK, Thornton AM, Casadei S, Rippey C, Shahin H, Consortium on the Genetics of Schizophrenia (COGS); PAARTNERS Study Group, et al. 2013. Spatial and temporal mapping of de novo mutations in schizophrenia to a fetal prefrontal cortical network. Cell 154: 518-529.

Hakonen AH, Isohanni P, Paetau A, Herva R, Suomalainen A, Lönnqvist T. 2007. Recessive Twinkle mutations in early onset encephalopathy with mtDNA depletion. Brain 130: 3032-3040.

Hakonen AH, Goffart S, Marjavaara S, Paetau A, Cooper H, Mattila K, Lampinen M, Sajantila A, Lönnqvist T, Spelbrink JN, et al. 2008. Infantile-onset spinocerebellar ataxia and mitochondrial recessive ataxia syndrome are associated with neuronal complex I defect and mtDNA depletion. Hum Mol Genet 17: $3822-3835$ 
Hartley JN, Booth FA, Del Bigio MR, Mhanni AA. 2012. Novel autosomal recessive c10orf2 mutations causing infantile-onset spinocerebellar ataxia. Case Rep Pediatr 2012: 303096.

Holmlund T, Farge G, Pande V, Korhonen J, Nilsson L, Falkenberg M. 2009. Structure-function defects of the twinkle amino-terminal region in progressive external ophthalmoplegia. Biochim Biophys Acta 1792: 132-139.

Isohanni P, Hakonen AH, Euro L, Paetau I, Linnankivi T, Liukkonen E, Wallden T, Luostarinen L, Valanne L, Paetau A, et al. 2011. POLG1 manifestations in childhood. Neurology 76: 811-815.

Koskinen T, Santavuori P, Sainio K, Lappi M, Kallio AK, Pihko H. 1994. Infantile onset spinocerebellar ataxia with sensory neuropathy: a new inherited disease. J Neurol Sci 121: 50-56.

Longley MJ, Humble MM, Sharief FS, Copeland WC. 2010. Disease variants of the human mitochondrial DNA helicase encoded by $\mathrm{C} 10 \mathrm{orf} 2$ differentially alter protein stability, nucleotide hydrolysis, and helicase activity. J Biol Chem 285: 29690-29702.

Lönnqvist T, Paetau A, Valanne L, Pihko H. 2009. Recessive twinkle mutations cause severe epileptic encephalopathy. Brain 132: 1553-1562.

McKinney EA, Oliveira MT. 2013. Replicating animal mitochondrial DNA. Genet Mol Biol 36: 308-315.

Milenkovic D, Matic S, Kühl I, Ruzzenente B, Freyer C, Jemt E, Park CB, Falkenberg M, Larsson NG. 2013. TWINKLE is an essential mitochondrial helicase required for synthesis of nascent D-loop strands and complete mtDNA replication. Hum Mol Genet 22: 1983-1993.

Morino H, Pierce SB, Matsuda Y, Walsh T, Ohsawa R, Newby M, Hiraki-Kamon K, Kuramochi M, Lee MK, Klevit RE, et al. 2014. Mutations in Twinkle primase-helicase cause Perrault syndrome with neurologic features. Neurology 83: 2054-2061.

Nikali K, Suomalainen A, Saharinen J, Kuokkanen M, Spelbrink JN, Lönnqvist T, Peltonen L. 2005. Infantile onset spinocerebellar ataxia is caused by recessive mutations in mitochondrial proteins Twinkle and Twinky. Hum Mol Genet 14: 2981-2990.

Nikkanen J, Forsström S, Euro L, Paetau I, Kohnz RA, Wang L, Chilov D, Viinamäki J, Roivainen A, Marjamäki P, et al. 2016. Mitochondrial DNA replication defects disturb cellular dNTP pools and remodel one-carbon metabolism. Cell Metab 23: 635-648.

Parikh S, Goldstein A, Koenig MK, Scaglia F, Enns GM, Saneto R, Anselm I, Cohen BH, Falk MJ, Greene C, et al. 2015. Diagnosis and management of mitochondrial disease: a consensus statement from the Mitochondrial Medicine Society. Genet Med 17: 689-701.

Park MH, Woo HM, Hong YB, Park JH, Yoon BR, Park JM, Yoo JH, Koo H, Chae JH, Chung KW, et al. 2014. Recessive C10orf2 mutations in a family with infantile-onset spinocerebellar ataxia, sensorimotor polyneuropathy, and myopathy. Neurogenetics 15: 171-182.

Prasad C, Melançon SB, Rupar CA, Prasad AN, Nunez LD, Rosenblatt DS, Majewski J. 2013. Exome sequencing reveals a homozygous mutation in TWINKLE as the cause of multisystemic failure including renal tubulopathy in three siblings. Mol Genet Metab 108: 190-194.

Sarzi E, Goffart S, Serre V, Chrétien D, Slama A, Munnich A, Spelbrink JN, Rötig A. 2007. Twinkle helicase (PEO1) gene mutation causes mitochondrial DNA depletion. Ann Neurol 62: 579-587.

Shutt TE, Gray MW. 2006. Twinkle, the mitochondrial replicative DNA helicase, is widespread in the eukaryotic radiation and may also be the mitochondrial DNA primase in most eukaryotes. J Mol Evol 62: 588-599.

Singleton MR, Sawaya MR, Ellenberger T, Wigley DB. 2000. Crystal structure of T7 gene 4 ring helicase indicates a mechanism for sequential hydrolysis of nucleotides. Cell 101: 589-600.

Toth EA, Li Y, Sawaya MR, Cheng Y, Ellenberger T. 2013. The crystal structure of the bifunctional primase-helicase of bacteriophage T7. Mol Cell 12: 1113-1123.

Walsh T, Shahin H, Elkan-Miller T, Lee MK, Thornton AM, Roeb W, Abu Rayyan A, Loulus S, Avraham KB, King $M C$, et al. 2010. Whole exome sequencing and homozygosity mapping identify mutation in the cell polarity protein GPSM2 as the cause of nonsyndromic hearing loss DFNB82. Am J Hum Genet 87: 90-94.

Yang Y, Muzny DM, Reid JG, Bainbridge MN, Willis A, Ward PA, Braxton A, Beuten J, Xia F, Niu Z, et al. 2013. Clinical whole-exome sequencing for the diagnosis of Mendelian disorders. N Engl J Med 369: 1502-1511. 


\section{COLD SPRING HARBOR Molecular Case Studies}

\section{Infantile onset spinocerebellar ataxia caused by compound heterozygosity for Twinkle mutations and modeling of Twinkle mutations causing recessive disease}

Sarah B. Pierce, Suleyman Gulsuner, Gail A. Stapleton, et al.

Cold Spring Harb Mol Case Stud 2016, 2: a001107 originally published online May 10, 2016

Access the most recent version at doi: $10.1101 / \mathrm{mcs} . a 001107$
References
This article cites 27 articles, 1 of which can be accessed free at:
http://molecularcasestudies.cshlp.org/content/2/4/a001107.full.html\#ref-list-1
License This article is distributed under the terms of the Creative Commons
Attribution-NonCommercial License, which permits reuse and redistribution, except for commercial purposes, provided that the original author and source are credited.
Email Alerting Receive free email alerts when new articles cite this article - sign up in the box at the Service top right corner of the article or click here.

